\title{
Pharmacogenomics and Heart Failure Patients on Carvedilol
}

\author{
Aya M. Bahgat Awad
}

\begin{abstract}
Department of Pharmacology faculty of medicine, Zagazig University, Egypt

Correspondence to: Aya M. Bahgat Awad, department of Pharmacology faculty of medicine, Zagazig University, Egypt

email:

ayabahgat11890@hotmail.com
\end{abstract}

Received: 24 July 2019

Accepted: 21 August 2019

\begin{abstract}
:
Pharmacogenomics is a science of how genes affect person's response to drugs. This field integrates pharmacology and genomics for development of safe and effective medications which tailored to person's genetic makeup. Genes are instructions, written in deoxyribonucleic acid (DNA), for constructing protein molecules. Diverse people can have various versions of the same gene.Cardiovascular diseases remain number one killer of mankind, and heart failure (HF) pays a fair contribution to this spectrum of diseases.Many options are available for the drug treatment in HF patients, with recent trends depending mainly on beta blockers (BBs) and angiotensin-converting-enzyme inhibitor (ACEIs) in addition to diuretics.BBs exert their effects by antagonizing the activation of $\beta$ ARs, and $\alpha$-ARs in case of carvedilol. Variations of these receptors can be involved in how HF patients with various genotypes respond to BBs. Therefore, we discuss some of the most commonly described single nucleotide polymorphisms (SNPs) in this review of literatures.
\end{abstract}

Keywords: Pharmacogenomics, Heart Failure, Carvedilol.

\section{Introduction and Rational}

Pharmacogenomics (PGx ) is a science of how genes affect person's response to drugs. This field integrates pharmacology and genomics for development of safe and effective medications which tailored to person's genetic makeup. Genes are instructions, written in deoxyribonucleic acid (DNA), for constructing protein molecules. ${ }^{[1]}$
Pharmacogenomics has the potential to influence clinically relevant outcomes in dosage, efficacy, and toxicity of drug which can cause subsequent recommendations for testing. For many routinely used drugs, pharmacogenomics has provided in conclusive evidence for this testing. ${ }^{[2]}$

A probable cause could be the including of both genetic and non genetic factors and their 
extent of contribution which detects the clinical relevance of some drugs. So, determination of genetic markers accompanied with drug reactions does not always link to clinically beneficial predictors of harmful outcomes, and most of time requires independent replication of association between genotype and phenotype prior pursuing clinical implementation. Absence of readily available resources, feasibility, utility, evidence level, provider knowledge, cost effectiveness, legal, ethical, and social issues further adds to the challenges and limitations of implementing pharmacogenomic testing in clinical practice. In order for genetic marker to be implicated in clinical practice, the association of genetic marker to particular trait requires tissues screening from many individuals, and corresponding functional studies are required to establish the probable association with the trait and phenotype. ${ }^{[3]}$

\section{Role of genes in how medicines work}

Genes are instructions, written in deoxyribonucleic acid (DNA), for constructing protein molecules. Diverse people can have various versions of the same gene. Each version has a slightly various DNA sequence. Some of them are common, and some are rare. And also some affect health, as those gene variants linked to particular diseases. ${ }^{[4]}$

Typically, people have two copies for each gene. Nevertheless, some people have hundreds or thousands copies of the CYP2D6 gene. Those with extra copies output too much of the CYP2D6 enzyme and address the drug very fast. Therefore, their bodies may convert codeine to morphine too quickly and completely which the standard dose can be an overdose. On the other hand, some variants of CYP2D6 create an enzyme which doesn't work. People with these variants address codeine slowly, if at all, causing little, if any, pain relief. For them, doctors can prescribe a various drug. ${ }^{[4]}$

Consequently, the US Food and Drug Administration (FDA) involves information about PGx associations in several drug labels in wide range of therapeutic areas. ${ }^{[4]}$ These PGx drug labels cover tests which are commonly used, however also include weaker genetic associations that are reported without needing adjustments to pharmaceutical treatment. Most of the drugs with mandatory genetic testing are utilized in oncology, but PGx tests in other therapeutic areas are already offered by laboratories and some become part of the standard clinical practice. ${ }^{[5]}$

Individualizing drug treatments through PGx testing could enhance their efficacy and safety, as well as decrease costs. ${ }^{[6]}$ But, as health-care resources are limited, it is important that cost effectiveness of novel PGx-guided treatment strategies is assessed in addition to their clinical utility prior they are widely

DOI: $10.21608 / \mathrm{bmfj} .2020 .15213 .1025$ 
implemented. Economic evaluations that compare costs and outcomes of at least two competing interventions are useful tool to inform decision making and prioritize healthcare expenditure. In the context of PGx testing, a pharmaco-economic study might contrast PGx-guided treatment with standard treatment with the same drug, or with an alternative drug which does not need genetic testing, or with both alternatives. When the PGx strategy is found to be more effective at acceptable additional cost (cost effectiveness) or more effective at lower cost (cost-saving or dominant), this offers strong argument for the PGx testing implementation. Previously published literature reviews of PGx-guided treatment and individualized medicine mentioned that the majority of PGx strategies were cost-effective or even dominant, though they reported that there was large heterogeneity between the methodologies of studies. ${ }^{[7]}$

Concerns over the quality of early economic evaluations of PGx-guided treatment have been increased, however the quality is generally considered to have optimized over time. ${ }^{[8]}$

Cardiovascular diseases remain the number one killer of mankind, and heart failure (HF) pays a fair contribution to this spectrum of diseases. According to American Heart Association (AHA), approximately 92.1 million adults in the USA have some form of cardiovascular diseases, and nearly 6.5 million adults above the age of 20 suffer from HF. Moreover, there are an additional 960,000 patients who develop HF each year. ${ }^{[9]}$ The patient load of HF reflects on the general mortality of the population, with 1 out of 9 deaths being attributed to $\mathrm{HF}^{[10]}$

\section{Drug therapy for $\mathbf{H F}$}

Numerous options are available for the drug treatment in $\mathrm{HF}$ patients, with recent trends mainly depending on BBs and ACEIs in addition to diuretics.

\section{Diuretics}

Diuretics are one of the bases of drug treatment in HF with symptoms. They improve symptoms and the quality of life. Diuretics are utilized in acute cases with higher doses in volume overload to improve symptoms as dyspnea and edema and in compensated HF to preserve a stable state. ${ }^{[11]}$

\section{Vasodilators}

Vasodilators reduce cardiac preload and afterload, therefore they improve cardiac systolic function and increase cardiac output.

\section{1- ACE inhibitors}

ACEI exhibit their vasodilator effect by decreasing the synthesis of angiotensin II (vasoconstrictor peptide) and increasing bradykinin through decreasing its inactivation. ACEI also reduces secondary hyperaldosteronism that happens in $\mathrm{HF}$, so 
decrease the edema in HF patients. They were also found to reduce cardiac remodeling. ${ }^{12}$ Enalapril significantly reduced mortality in (26\% vs. $44 \%$ after 6 months). ACEI should be started with low doses beyond the correction of hyponatremia or volume depletion in elderly to prevent severe hypotension and renal insufficiency. Diuretics dose may rise transiently after arriving the maintenance dose of ACEI. Later, diuretics dose may be reduced again. ${ }^{[13]}$

\section{2- ARBs}

Angiotensin II is potent vasoconstrictor which may affect LV function and result in $\mathrm{HF}$ worsening through raised resistance of $\mathrm{LV}$ emptying, long-term structural impacts on the heart and vasculature and activation of other neuro-hormonal agonists, involving noradrenalin, aldosterone, and endothelin. ${ }^{[14]}$

The ARB losartan decreased the hospitalization rate for HF by $32 \%$, compared with placebo, at follow up of patients with type-2 diabetes and nephropathy. Also, losartan reduced HF hospitalization by $41 \%$ compared with atenolol at follow up of patients with diabetes, hypertension and LV hypertrophy. ${ }^{[15]}$

\section{3- Sacubitril/valsartan combination}

In the previous few years, a novel drug class of "angiotensin receptor-neprilysin inhibitor (ARNI)" emerged in HF treatment (fig. 1).
The first and to date only substance in this class is "LCZ696" and consists of ARB (valsartan) and neprilysin inhibitor (sacubitril). ${ }^{[16]}$ The PARADIGM-HF (Prospective Comparison of ARNI with ACEI to Detect Effect on Global Mortality and Morbidity in HF) trial compared therapy with sacubitril/valsartan therapy and with ACEI enalapril. Cardiovascular mortality and hospitalizations for HF were significantly decreased in the sacubitril/valsartan group (20\%). ${ }^{[17]}$ The overwhelming impacts have caused in the 2016 ACC/AHA/HF Society of America updated guidelines state with class I recommendation which sacubitril/valsartan may be utilized alternative to ACEI or ARB in chronic symptomatic HF class II or III to further decrease morbidity and mortality. ${ }^{[18]}$

In addition to the typical adverse effects of the treatment (hypotension, renal insufficiency, hyperkalemia), it should be kept in mind, especially regarding elderly, that sacubitril/ valsartan gives rise significantly higher incidence of hypotension with symptoms than treatment with ACEI. Therefore, patients have very low blood pressure during ACEI therapy should not be shifted to an ARNI. ${ }^{[19]}$

\section{4- Isosorbidedinitrate plus hydralazine}

Numerous studies demonstrated the dependence of ventricular function on vascular resistance, and drugs which decreased systemic vascular resistance enhance cardiac

DOI: $10.21608 / \mathrm{bmfj} .2020 .15213 .1025$ 
performance. So, studies were searching for that this combination can produce mortality drugs combinations that could be beneficial in benefits. ${ }^{[20,21]}$

reducing vascular resistance, when they found

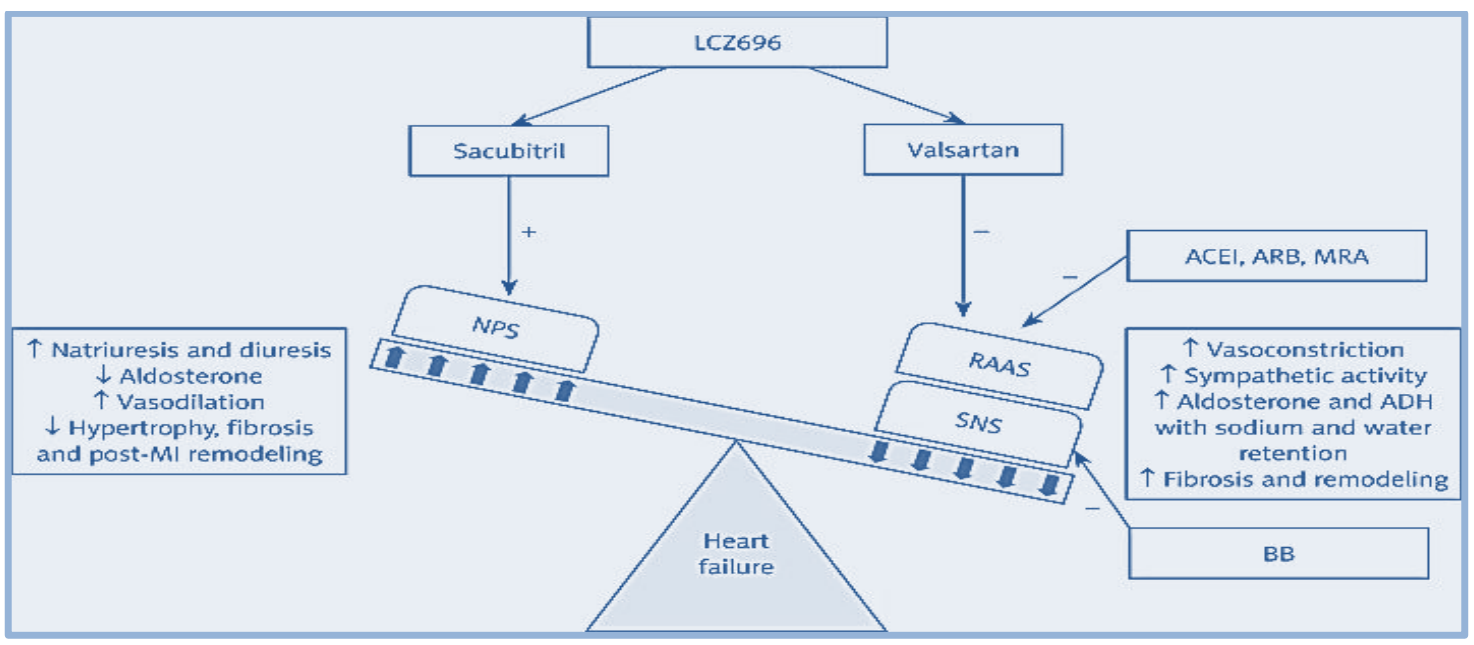

Figure (1): Sacubitril/valsartan combination in HF therapy. ${ }^{20}$

Oral nitrates decrease preload and pulmonary congestion in HF patients. Hydralazine decrease afterload, promoting perfusion at the same level for filling pressure of LV. ${ }^{[13]}$

The ACC/AHA guidelines recommend utilizing isosorbidedinitrate and hydralazine in African American HF patients with NYHA class III or IV who treated with diuretics, ACE inhibitors, and BBs. These guidelines recommend the use of isosorbidedinitrate and hydralazine in symptomatic HF patients who cannot be given ACE inhibitor or ARB due to drug intolerance, hypotension, or renal impairment. ${ }^{[18]}$

\section{Mineralocorticoid receptor antagonists (MRA)}

MRAs counteract the 2ry hyperaldosteronism of $\mathrm{HF}$, they also reduce the hypokalemia induced by other diuretics. ${ }^{22}$
Since the Randomized Aldactone Evaluation Study (RALES) trial and the Eplerenone PostAcuteMyocardial Infarction Heart Failure Efficacy and Survival Study (EPHESUS-HF) trial treatment with MRA for symptomatic HF patients, although treated with ACEI and BB, is established and implemented in this guidelines. ${ }^{[16]}$ Subgroup analyses in both the RALES and the EMPHASIS-HF trial have shown that older patients with HF benefit from therapy with MRA to a similar extent as younger patients with HF. ${ }^{[23]}$ Hyperkalemia is the most important side effect of MRA therapy. Especially in elderly, renal markers and electrolytes should be monitored regularly, particularly with concomitant medication with $\mathrm{ARB}$ or ACEI. Older age is independent risk factor in developing hyperkalemia. ${ }^{\text {[24] }}$ 


\section{If -channel inhibitor (ivabradine)}

Ivabradine decrease the heart rate through inhibition of the If channel in the sino-atrial node. In the Systolic Heart Failure Treatment with the If inhibitor Ivabradine (SHIFT) trial, additional administration of ivabradine with optimized HF medication caused significant reduction in hospitalizations for $\mathrm{HF}$ and cardiovascular mortality leading to a corresponding recommendation in the present guidelines. ${ }^{[11]}$

\section{Inotropic therapy}

Inotropic therapy was proved to raise mortality in HF patients. Positive inotropic drugs other than digoxin should not be utilized to treat patients with chronic HF unless they used for palliative treatment or as a bridge for cardiac transplantation. These drugs can be utilized for short duration in acute decompensated HF and life-threatening situations. ${ }^{[13]}$

\section{Digitalis}

Advanced HF Patients (NYHA III-IV, LVEF $<25 \%$ ) and patients with high ventricular rate and atrial fibrillation seem to profit from therapeutic use of cardiac glycosides as regard hospitalization rates and mortality. ${ }^{[25]}$ Because of the limited therapeutic range of cardiac glycosides, they are used with caution particularly in elderly, and digitoxin is preferred especially in impaired renal function patients. ${ }^{[11]}$

\section{BBs}

Continuous increase in the adrenergic drive found in the failing human heart delivers adverse biological signals to the myocytes of heart through $\beta_{1^{-}}, \beta_{2^{-}}$and $\alpha_{1^{-a d r e n e r g i c}}$ receptors. This is the main basis for the $\mathrm{BBs}$ usage in $\mathrm{HF}$ management. Interrupting this activated sympathetic nervous system with $\mathrm{BBs}$ is approach to change the natural course of HF. ${ }^{[26]}$

BBs act by reversibly antagonizing the actions that occur as a result of stimulation of $\beta$-ARs. The BBs that showed the most significant evidence for improvement in cardiac functions and mortality benefits are metoprolol, carvedilol, and bisoprolol. While bisoprolol and metoprolol are cardioselective $\mathrm{BBs}$ that preferentially inhibit $\beta 1-\mathrm{ARs}$, carvedilol is a non-selective $\mathrm{BB}$ which has $\alpha 1-\mathrm{AR}$ antagonistic activity as well. Numerous clinical trials were performed to assess BBs efficacy in HF. ${ }^{[27]}$

BBs now are widely used in the therapy of HF. BBs reduce mortality in HF patients. At 32month follow up for 1,369 HF patients with NYHA class II or III, compared with placebo, nebivolol was found to reduce all-causes of cardiovascular hospital admission or mortality by $14 \% .^{[28]}$

Several trials have investigated BBs efficacy in HF patients. In one trial, nebivolol treatment was compared with placebo. Treatment with

DOI: $10.21608 / \mathrm{bmfj} .2020 .15213 .1025$ 
nebivolol caused a remarkable decrease in the primary endpoint all-cause of cardiovascular hospitalizations and mortality. ${ }^{[28]}$ Another trial compared treatment with carvedilol and bisoprolol in patients with mean age of 73 years. No variations were found as regard achieved target dose or tolerance; however patients on bisoprolol more often complained from bradycardias, while carvedilol caused decreased forced expiratory volume (FEV). This should be taken into consideration when choosing the "individual" BB. Elderly with heart rate in the range of 55-64 bpm had the lowest mortality. ${ }^{[29]}$

Before starting treatment with BBs, patients should be treated with an ACE inhibitor or $\mathrm{ARB}$ and be in a relatively stable condition without the need of intravenous inotropic therapy and without signs of marked fluid retention. BBs should be initiated in a low dose. The dose of BBs should then be doubled at two to three week intervals, with the maintenance dose of $\mathrm{BBs}$ reached over three months (carvedilol $25 \mathrm{mg}$ twice daily or $50 \mathrm{mg}$ twice daily if over 85 kilograms or metoprolol CR/XL $200 \mathrm{mg}$ once daily). The patient may suffer fatigue during the initiation or uptitration of the BB dose. ${ }^{[30]}$

During titration, the patient should be checked for HF symptoms, fluid retention, hypotension, and bradycardia. If there is any worsening of symptoms, the dosage of diuretics or ACE inhibitors' should be raised and the BBs dose should be temporarily decreased if necessary. If there is hypotension, the vasodilators dose should be reduced and the BBs dose temporarily decreased if necessary. Reduction or discontinuation of drugs which may reduce heart rate should be considered in the presence of bradycardia. Contraindications to the BBs use in HF patients are asthma, severe bronchial disease, and symptomatic bradycardia and hypotension. ${ }^{[13]}$

\section{Carvedilol}

Apart from blocking $\beta$-adrenoreceptors, carvedilol also offers multiple cardioprotective influences, as antioxidant, vasodilatory, anti-inflammatory, antiapoptotic, anti-proliferative and cardiac remodeling attenuation effects, all of which have role in HF management. ${ }^{[31]}$ Numerous randomized trials demonstrated that carvedilol shows a better metabolic profile than metoprolol in patients with type 2 diabetes, metabolic syndrome and overweight, as well as maintain kidney function in patients with CKD. ${ }^{[32]}$

Carvedilol is found in the market as racemic mixture in which nonselective $\beta$ - blocking activity is found in the $S(-)$ enantiomer and $\alpha-$ adrenergic blocking activity is found in both $\mathrm{R}$ (+) and S (-) enantiomers at equal potency. Carvedilol has no intrinsic sympathomimetic activity.

Carvedilol is rapidly and extensively absorbed after oral administration, with bioavailability 
of about $25 \%$ to $35 \%$ as result of a significant degree of first pass metabolism. Beyound oral administration, the elimination half-life of carvedilol ranges from seven to 10 hours. When given with food, the rate of absorption is decreased, so taking carvedilol with food should reduce the orthostatic hypotension risk. [33]

Carvedilol is extensively primarily metabolized by oxidation. The oxidative metabolites are then metabolized by conjugation with glucuronidation and sulfation. The metabolites of carvedilol are excreted primarily by the bile into feces. Demethylation and hydroxylation at the phenol ring produce three active metabolites with $\beta$-receptor blocking activity. Depend on preclinical studies, the 4'-hydroxyphenyl metabolite is about 13 folds more potent than carvedilol for $\beta$-blockade and weaker vasodilating activity. ${ }^{[33]}$

Plasma levels of the active metabolites are approximately one-tenth of those observed for carvedilol and have pharmacokinetics as the parent. The primary P450 enzymes responsible for the metabolism of both $\mathrm{R}(+)$ and $\mathrm{S}(-)$ carvedilol in liver microsomes of human were CYP2D6 and CYP2C9 and to lesser extent CYP3A4, 2C19, 1A2, and 2E1. CYP2D6 is thought to be the major enzyme in the 4'- and 5'-hydroxylation of carvedilol, with potential contribution from $3 \mathrm{~A} 4$. CYP2C9 is thought to be of the primary importance in the $\mathrm{O}$ methylation pathway of S(-)-carvedilol. ${ }^{[33]}$

Carvedilol is placed to the influences of genetic polymorphism with poor metabolizers (PMs) of debrisoquin (a marker for cytochrome P450 2D6) exhibiting two to three times higher plasma levels of $\mathrm{R}(+)$-carvedilol compared to extensive metabolizers (Ems). In contrast, plasma concentrations of $\mathrm{S}(-)$ carvedilol are raised only about $20 \%$ to $25 \%$ in PMs, indicating this enantiomer is metabolized to lesser extent by cytochrome P450 2D6 than $\mathrm{R}(+)$-carvedilol. The carvedilol pharmacokinetics do not appear to be different in PMs of S-mephenytoin (patients with deficiency in cytochrome P450 2C19). ${ }^{[33]}$

\section{Pharmacogenomics and $\beta$-ARs}

As previously mentioned, BBs exert their effects by antagonizing the activation of $\beta$ ARs, and $\alpha$-ARs in case of carvedilol. Variations of these receptors can be involved in how HF patients with different genotypes respond to BBs. We discuss some of the most commonly described single nucleotide polymorphisms (SNPs). ${ }^{[34]}$

\section{B-1 Adrenergic Receptors (ADRB-1)}

\section{Arg389Gly polymorphisms}

ADRB-1 is the predominant types of receptors on the myocardium, which makes them a target of BBs therapy for cardiac and $\mathrm{HF}$ patients. Activation of these receptors causes 
increases in the heart rate and contractility. Variations of type ADRB-1 have been hypothesized to not only be a predictor of HF, but also of response to BBs and their efficacy in different patients. ${ }^{[35]}$

ADRB-1 are comprised of 477 amino acids that are encoded by a gene on chromosome 10q24-26. One of the most commonly described SNPs is the Arg389Gly, in which guanine is substituted by cytosine at residue 389 , thus exchanging arginine by glycine at the intracellular C-terminus of the receptor. The Arg389 phenotype is believed to be associated with higher levels of adenyl cyclase activity and greater Gs coupling compared to Gly389, which has less affinity for Gs. ${ }^{[36]}$ Numerous studies have made it their subject to try to establish the role of Arg389Gly polymorphisms in the response of patients to BBs. Another study by Baudhuin et al. for instance, proposed that the polymorphisms in ADRB-1 were associated with variations in the dose of beta carvedilol, but not with any difference in response to the BBs metoprolol and carvedilol. ${ }^{[37]}$

\section{Ser49Gly polymorphisms}

Another commonly described SNP is that which occurs at residue 49 of the ADRB, in which serine is substituted by glycine at the amino terminus. The Ser49Gly polymorphisms have been suggested to predict response to BBs therapy, since the Gly49 genotype expressed greater down-regulation of the receptor when stimulated by agonists. ${ }^{[38]}$

\section{$\beta$-2 Adrenergic Receptors (ADRB-2):}

The ADRB-2 is a 413 residue protein that is encoded by the q31-q32 gene on chromosome 5. While they are not the predominant receptors in healthy myocardium, the disrupted balance in $\mathrm{HF}$ due to down-regulation of ADRB-1 leads to over expression of the ADRB-2. [39]

Stimulation of the ADRB-2 in the myocardium leads to positive chronotropic and inotropic effects, as well as anti-apoptotic effects. Their activation in blood vessels, on the other hand, leads to smooth muscle relaxation. Genetic variations of ADRB-2 have been hypothesized to play a role in response to BBs. SNPs at amino acid positions 16(Arg16Gly), 27 (Gln27Glu), and 164 (Thr164Ile) are the most often described, with the Gln27Glu polymorphism having the strongest evidence. Several studies implied that patients who carried the Glu27 allele showed greater improvements in left-ventricular ejection fraction(LVEF) and decrease in heart rate on carvedilol when compared to Gln27. ${ }^{[40]}$

\section{References}

1. Joseph P. Kitzmiller, David K. Groen, Mitch A. Phelps, And Wolfgang Sadee, Pharmacogenomic testing: Relevance in medical practice. Cleve Clin J Med. 2011 Apr; 78(4): 243-257.

2. John D Blakeyand Ian P Hall. Current progress in pharmacogenetics Br J ClinPharmacol. 2011 Jun; 71(6): 824-831. 
3. YogitaA.Ghodke-Puranikand

JatinderK.LambaInnovative Approaches in Drug DiscoveryEthnopharmacology, Systems Biology and Holistic TargetingPharmacogenomics Chapter 7 2017, Pages 195-234.

4. National Institute of General Medical Sciences.PharmacogenomicsAt https://www.nigms.nih.gov/education/pages/fa ctsheet-pharmacogenomics.aspx

5. Centers for Disease Control and Prevention. Genomic Tests and Family HealthHistory by Levels of Evidence: Public Health Genomics. Availableathttp://www.

cdc.gov/genomics/gtesting/tier.htm (accessed on 17 February 2016).

6. Haycox A, Pirmohamed M, McLeod C, Houten R, Richards S. Through a glass darkly:economics and personalised medicine. Pharmacoeconomics 2014; 32: 1055-1061.

7. Phillips KA, Van Bebber SL. A systematic review of cost-effectiveness analyses ofpharmacogenomic interventions. Pharmacogenomics 2004; 5: 1139-1149.

8. Shabaruddin FH, Fleeman ND, Payne K. Economic evaluations of personalized medicine: existing challenges and current developments. PharmacoEcon Personalized Med 2015; 8: 115-126.

9. Abbate A, Salloum FN, Vecile E, Das A, Hoke NN, Straino S, Giuseppe G L, Biondi-Zoccai Houser JE, Qureshi IZ, Ownby ED, Gustini E, Biasucci LM, Dobrina A (2008): Anakinra, a recombinant human interleukin-1 receptor antagonist, inhibits apoptosis in experimental acute myocardial infarction. Circulation; 117(20): 2670-2683.

10. Ghali JK, Krause-Steinrauf HJ, Adams KF, Khan SS, Rosenberg YD, Yancy CW, Young JB, Goldman S, Peberdy MA, Lindenfeld J (2003): Gender Differences in Advanced Heart Failure: Insights from the BEST Study. Journal of the American College of Cardiology; 42(12): 2128-2134.

11. Ponikowski P, Voors AA, Anker SD, Bueno H, Cleland JGF, Coats AJS, Falk V, GonzálezJuanatey JR, Harjola V-P, Jankowska EA, Jessup M, Linde C, Nihoyannopoulos P, van der Meer P (2016): 2016 ESC Guidelines for the diagnosis and treatment of acute and chronic heart failure. European Journal of Heart Failure; 18(8): 891-975.

12. Irhuma MOE and Vally M (2016): Use of angiotensin receptor - neprilysin inhibitors in heart failure : a paradigm shift; 58(5): 60-63.
13. Aronow WS (2017): Treatment of Heart Failure with Abnormal Left Ventricular Systolic Function in Older Adults. Heart Failure Clinics. https://doi.org/10.1016/j.hfc.2017.02.004

14. Jilma B, Krejcy K, Dirnberger E, Eichler H-G, Kapiotis S, Dorner GT, Wagner OF (1997): Effects of angiotensin-II infusion at pressor and subpressor doses on endothelin-1 plasma levels in healthy men. Life Sciences; 60(21): 1859-1866.

15. Lindholm LH, Ibsen H, Dahlöf B, Devereux RB, Beevers G, De Faire U, Fyhrquist F, Julius $\mathrm{S}$, Kjeldsen SE, Kristiansson K, LederballePedersen O, Nieminen MS, Omvik P, Snapinn $S$ (2002): Cardiovascular morbidity and mortality in patients with diabetes in the Losartan Intervention For Endpoint reduction in hypertension study (LIFE): A randomised trial against atenolol. Lancet; 359(9311): 1004-1010.

16. Berliner D and Bauersachs J (2018): Drug treatment of heart failure in the elderly. Herz. https://doi.org/10.1007/s00059-017-4668-9

17. McMurray JJV, Packer M, Desai AS, Gong J, Lefkowitz MP, Rizkala AR, Rouleau JL, Shi VC, Solomon SD, Swedberg K, Zile MR (2014): Angiotensin-Neprilysin Inhibition versus Enalapril in Heart Failure. New England Journal of Medicine; 371(11): 993-1004.

18. Yancy CW, Jessup M, Bozkurt B, Butler J, Casey DE, Colvin MM, Drazner MH, Filippatos G, Fonarow GC, Givertz MM, Hollenberg SM, Lindenfeld J, Masoudi FA, McBride PE, Peterson PN, Stevenson LW, Westlake, C. (2016): 2016 ACC/AHA/HFSA Focused Update on New Pharmacological Therapy for Heart Failure: An Update of the 2013 ACCF/AHA Guideline for the Management of Heart Failure. Journal of the American College of Cardiology; 68(13): 1476-1488.

19. Dec GW (2015): LCZ696 (Sacubitril/Valsartan) Can We Predict Who Will Benefit? J Am CollCardiol.; 66(19):20722074.

20. Yandrapalli S, Aronow WS, Mondal P, Chabbott DR (2017): The evolution of natriuretic peptide augmentation in management of heart failure and the role of sacubitril/valsartan. Archives of Medical 
Science; 13(5): 1207-1216.

21. Taylor, A. L., Ziesche, S., Yancy, C., Carson, P., D’Agostino, R., Ferdinand, K., Taylor, M., Adams, K., Sabolinski, M., Worcel, M., \& Cohn, J. N. (2004). Combination of IsosorbideDinitrate and Hydralazine in Blacks with Heart Failure. N Engl J Med.; 351(20): 2049-57.

22. Nappi JM and Sieg A (2011): Aldosterone and aldosterone receptor antagonists in patients with chronic heart failure. Vasc Health Risk Manag.; 7: 353-63.

23. Lee D, Wilson $\mathrm{K}$, Akehurst R, Cowie MR, Zannad F, Krum H, Van Veldhuisen DJ, Vincent J, Pitt B, McMurray JJV (2014): Costeffectiveness of eplerenone in patients with systolic heart failure and mild symptoms. Heart; 100(21): 1681-1687.

24. Lindenfeld J, Albert NM, Boehmer JP, Collins SP, Ezekowitz JA, Givertz MM, Katz SD, Klapholz M, Moser DK, Rogers JG, Starling RC, Stevenson WG, Tang WHW, Walsh MN (2010): HFSA 2010 Comprehensive Heart Failure Practice Guideline. Journal of Cardiac Failure; 16: e1-e194.

25. Gheorghiade M, Patel K, Filippatos G, Anker SD, Van Veldhuisen DJ, Cleland JGF, Metra M, Aban IB, Greene SJ, Adams KF, McMurray JJV, Ahmed A (2013): Effect of oral digoxin in high-risk heart failure patients: A pre-specified subgroup analysis of the DIG trial. European Journal of Heart Failure; 15(5): 551-559.

26. Porapakkham P, Porapakkham P, Krum H (2010): Is target dose of beta-blocker more important than achieved heart rate or heart rate change in patients with systolic chronic heart failure? Cardiovascular Therapeutics; 28(2): 93-100.

27. Kubon C, Mistry NB, Grundvold I, Halvorsen S, Kjeldsen SE, Westheim AS (2011): The role of beta-blockers in the treatment of chronic heart failure. Trends PharmacolSci; 32(4): $206-$ 12.

28. Flather MD, Shibata MC, Coats AJS, Veldhuisen DJ Van, Parkhomenko A, Borbola J, Cohen-Solal A, Dumitrascu D, Ferrari R, Lechat P, Soler-Soler J, Tavazzi L, Spinarova L, Poole-Wilson PA (2005): Randomized trial to determine the effect of nebivolol on mortality and cardiovascular hospital 37. Baudhuin LM, Miller WL, Train L, Bryant S, admission in elderly patients with heart failure (SENIORS). European Heart Journal, 26(26), 215-225.

29. Düngen HD, Musial-Bright L, Inkrot S, Apostolovï̈ S, Edelmann F, Lainščak M, Šekularac N, Störk S, Tahirovic E, Tscholl V, Krackhardt F, Loncar G, Trippel TD, Gelbrich G (2014): Heart rate following short-term betablocker titration predicts all-cause mortality in elderly chronic heart failure patients: Insights from the CIBIS-ELD trial. European Journal of Heart Failure; 16(8): 907-914.

30. Remme WJ and Swedberg K (2001): Guidelines for the diagnosis and treatment of chronic heart failure. European Heart Journal; 22(17): 1527-1560.

31. Chen-Scarabelli C, Saravolatz L, Murad Y, Shieh W-S, Qureshi W, Di Rezze J, Abrencillo R, Gardin T, Gidwani U, Faggian G, Scarabelli $T$ (2012): A Critical Review of the Use of Carvedilol in Ischemic Heart Disease. Am J Cardiovasc Drugs. Retrieved fromhttp://ovidsp.ovid.com/ovidweb.cgi?

32. Poole-Wilson PA, Swedberg K, Cleland JGF, Di Lenarda A, Hanrath P, Komajda M, Lubsen J, Lutiger B, Metra M, Remme WJ, TorpPedersen C, Scherhag A, Skene A (2003): Comparison of carvedilol and metoprolol on clinical outcomes in patients with chronic heart failure in the CarvedilolOrMetoprolol European Trial (COMET): Randomised controlled trial. Lancet; 362(9377): 7-13.

33. Morgan T (1994): Clinical Pharmacokinetics and Pharmacodynamics of Carvedilol. Clinical Pharmacokinetics; 26(5): 335.

34. Luzum JA, Sweet KM, Binkley PF, Schmidlen TJ, Jarvis JP, Christman MF, Sadee W, Kitzmiller JP (2017): CYP2D6 Genetic Variation and Beta-Blocker Maintenance Dose in Patients with Heart Failure. Pharm Res.; 34(8): 1615-1625.

35. Liu W-N, Fu K-L, Gao H-Y, Shang Y-Y, Wang Z-H, Jiang G-H, Zhang Y, Zhang W, Zhong M (2012): $\beta 1$ adrenergic receptor polymorphisms and heart failure: a metaanalysis on susceptibility, response to $\beta$ blocker therapy and prognosis. PloS One; 7(7): e37659.

36. Femminella GD, Barrese V, Ferrara N, Rengo G (2014): Tailoring therapy for heart failure: The pharmacogenomics of adrenergic receptor signaling. Pharmacogenomics and Personalized Medicine; 7:267-73.

Hartman KA, Phelps M, LaRock M, Jaffe AS 
(2010): Relation of ADRB1, CYP2D6, and UGT1A1 polymorphisms with dose of, and response to, carvedilol or metoprolol therapy in patients with chronic heart failure. American Journal of Cardiology; 106(3): 402-408.

38. Levin MC, Marullo S, Muntaner O, Andersson B, Magnusson Y (2002): The myocardiumprotective Gly-49 variant of the $\beta 1$-adrenergic receptor exhibits constitutive activity and increased desensitization and down-regulation. Journal of Biological Chemistry; 277(34): 30429-35.

39. Ciccarelli M, Chuprun JK, Rengo G, Gao E, Wei Z, Peroutka RJ, Gold JI, Gumpert A, Chen M, Otis NJ, Dorn GW, Trimarco B, Iaccarino
G, Koch WJ (2011): G protein-coupled receptor kinase 2 activity impairs cardiac glucose uptake and promotes insulin resistance after myocardial ischemia. Circulation; 123(18): 1953-1962.

40. Troncoso R, Moraga F, Chiong M, Roldán J, Bravo R, Valenzuela R, Díaz-Araya G, Del Campo A, Sanhueza C, Rodriguez A, Vukasovic J L, Mellado R, Greig D, Lavandero S (2009): Gln27 $\rightarrow$ Gluß2-adrenergic receptor polymorphism in heart failure patients: Differential clinical and oxidative response to carvedilol. Basic and Clinical Pharmacology and Toxicology; 104(5): 374-378.

To cite this article: Aya M. Bahgat Awad, Pharmacogenomics and Heart Failure Patients on Carvedilol, BMFJ 2019;36(3):77-88 DOI: 10.21608/bmfj.2020.15213.1025 